\title{
Predicting thermal sensation through local body skin temperatures to assess thermal comfort: a short systematic review
}

\author{
R. P. Martins ${ }^{1}$, Daniele Costa², J. C. Guedes ${ }^{3}$
}

${ }^{1}$ Associated Laboratory for Energy, Transports and Aeronautics (PROA/LAETA), Faculty of Engineering, University of Porto, PT (rpmar@fe.up.pt) ORCID 0000-0001-8438-0597, ${ }^{2}$ Faculty of Engineering, University of Porto, PT (daniele.costa@fe.up.pt), ${ }^{3}$ Associated Laboratory for Energy, Transports, and Aeronautics (PROA/LAETA), Faculty of Engineering, University of Porto, PT (jccg@fe.up.pt) ORCID 0000-0003-2367-2187 https://doi.org/10.24840/978-972-752-260-6_0082-0087

\begin{abstract}
Introduction: The skin plays a substantive role in the thermoregulatory process. The maintenance of a constant internal body temperature by the thermoregulatory system, partially achieved by vasoconstriction and vasodilation, makes the skin temperature an important mechanism to indicate the thermal state of the comfort of a given subject. However, this parameter is still little considered in studies that evaluate thermal comfort. Therefore, this work aims to investigate the use of skin temperatures as a predictor of thermal sensation to assess thermal comfort. Methodology: A short systematic review based on Preferred Reporting Items for Systematic Reviews and Meta-Analyses (PRISMA) was performed to assess scientific publications that evaluated thermal comfort considering the skin temperature as a predictor. The review search strategy considered the use of "thermal comfort" and "skin temperature" as keywords in the 'Web of Science', 'Scopus', 'PubMed', and 'Academic Search Ultimate', 'Taylor and Francis' and 'Sage Journals' databases. Eligibility criteria considered articles that conducted experiments under steady-state environmental conditions and that considered skin temperature measurements in the assessment of thermal comfort. Results and Discussion: The search resulted in the identification of 73 articles, from which five were considered suitable for the systematic review. Skin temperatures were measured at a variety of measurement points throughout the reviewed articles. Overall, the mean skin temperature of female subjects was lower than the mean skin temperature of male subjects at each experimental temperature, at the same level of thermal comfort. Forehead, chest and abdomen were evidenced as the best measuring points and presented the highest correlation between thermal sensation and skin temperature. Conclusion: The systematic review has shown that the comparison between the selected articles is hampered by the lack of uniformity in the adopted experimental procedures. There seems to be a relationship between thermal sensation and skin temperature responses. Future studies should consider more uniform experimental procedures. Besides, there is the need of increasing the size of the experimental sample and to consider different target groups (such as children or the elderly) to verify if the prediction of thermal comfort based on skin temperature exhibits the same trends when compared to healthy adults.
\end{abstract}

Keywords: Skin temperature, Thermal comfort, Thermal sensation vote, Systematic review.

\section{INTRODUCTION}

Humans are highly sensitive to thermal conditions, which affects the physiological state, the mood, and behaviour of individuals (Parsons, 2003). The maintenance of constant internal body temperature by the thermoregulatory system is partly achieved through the mechanism of vasoconstriction and vasodilation (De Dear, Ring \& Fanger, 1993). These processes may decrease or increase skin blood flow to prevent heat loss or to dissipate heat, respectively, protecting the body against heat stress or hypothermia (Charkoudian, 2003), resulting in decreased or increased body temperature. Due to these mechanisms, the skin temperature acts as a parameter to indicate the thermal state of the comfort of a given subject. Thermal comfort is defined by ASHRAE (2010) as the "condition of mind that expresses satisfaction with the thermal environment and is assessed by subjective evaluation". Such assessment of thermal comfort often considers a thermal index to describe, design and assess thermal environments as experienced by individuals. In this context, skin temperature measurements are a relevant physiological parameter to be considered in the assessment of thermal comfort. However, the relationship between skin temperature and thermal comfort is still poorly evaluated in the scientific literature. Considering these aspects, the scope of this short systematic review is to investigate the use of skin temperatures as a thermal sensation predictor to assess thermal comfort. 


\section{METHODOLOGY}

This short systematic review considered the Preferred Reporting Items for Systematic Reviews and Meta-Analyses, or simply PRISMA Statement, to conduct the review (Moher et al., 2009b). "Thermal comfort" and "skin temperature" were the defined search keywords. The search was conducted in the title search field of the search mechanism in the following databases: Web of Science, Scopus, PubMed, Academic Search Ultimate, Taylor and Francis, and Sage Journals. Once the search was completed, resulting in a total of 73 publications, which were exported from the databases and inserted into a bibliographic management software for screening. At first, all duplicate records were eliminated (40 publications). Then, the title and abstracts were examined, taking into consideration the inclusion criteria. The search considered only peerreviewed scientific publications and articles published until April of 2019. A limitation of years of publication was not included to allow a more extensive identification of the existing scientific publications. All grey literature identified (conference articles, editorials, among others) was excluded since their quality is not certified by an expert peer-review process. Only articles written in English were included. Later, articles fulfilling the scope of the study were retrieved and assessed (19 articles). To be considered eligible, experiments should only be performed under steady-state environmental conditions (studies conducted in transient and non-uniform environmental conditions were not included). Only studies correlating skin temperature and the assessment of thermal comfort through thermal sensation were considered. The inclusion criteria only considered studies with human subjects but did not focus on a specific population of participants, disregarding their age group. A total of five articles were considered eligible and were discussed in the qualitative synthesis. The selection details of all relevant articles are shown in Figure 1.

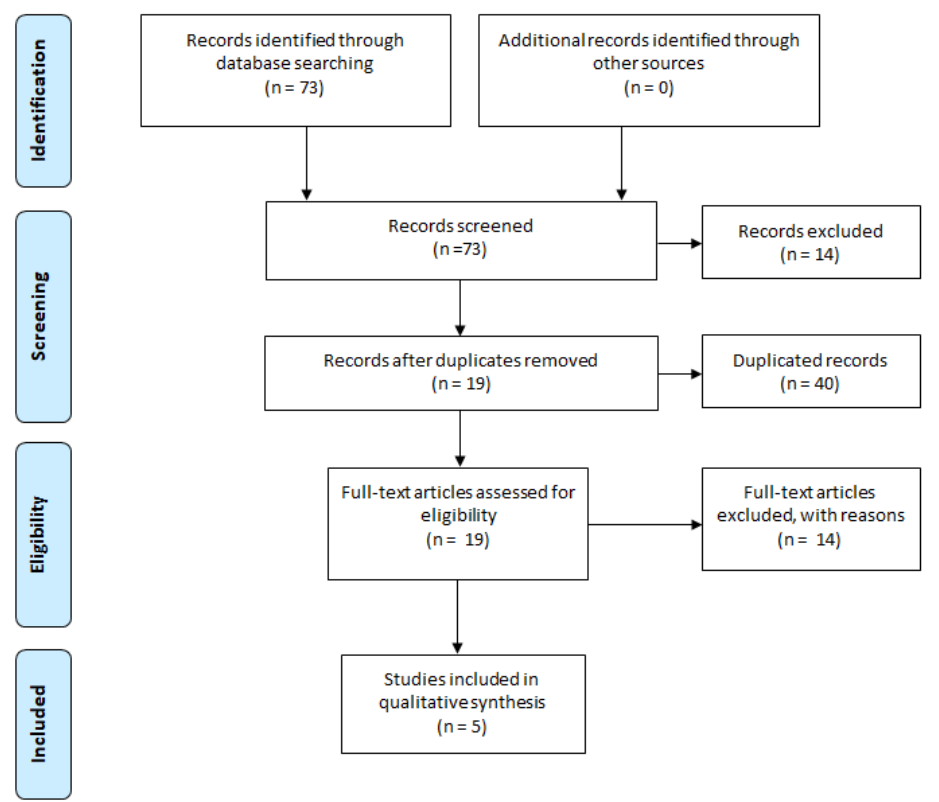

Figure 1. PRISMA Flowchart Diagram. Source: authors based on Moher et al. (2009) 


\section{RESULTS AND DISCUSSION}

This systematic review identified five articles with the scope of this study. The selected articles were published from 2007 to 2018. Regarding the geographical location, four articles were from China (Yao et al., 2007; Liu et al., 2011; Liu et al., 2015; Fang et al., 2018), and one from Poland (Bogdan, 2011). All articles conducted experiments in healthy adult humans.

\section{Sample characteristics}

The characteristics of the sample population are presented in Table 1. Except for Bogdan (2011), all articles considered both male and female in the experiments. All the assessed articles considered a relatively young population (minimum of 20.5 and a maximum of 28.3 years), with a weight range between 47.0 to $83.1 \mathrm{~kg}$. The number of participants is relatively small in all articles, which is reflected in a reduced confidence interval in their findings. All adopted protocols were approved by an ethics committee. Information on the given consent of participants to participate in the experiments is reported in all of the reviewed articles, except for Bogdan (2011).

\begin{tabular}{|c|c|c|c|c|}
\hline Reference & Sample & Age (years) & Height $(\mathrm{cm})$ & Weight (kg) \\
\hline Bogdan, 2011 & $14 \mathrm{M}$ & $22 \pm 1.5$ & $181 \pm 35$ & $75.6 \pm 7.5$ \\
\hline Fang et al., 2018 & $8 \mathrm{M}, 8 \mathrm{~F}$ & $23.81 \pm 1.27$ & $167 \pm 7$ & $57.25 \pm 7.99$ \\
\hline Liu et al., 2015 & $12 \mathrm{M}, 10 \mathrm{~F}$ & $23.9 \pm 0.4$ & $170 \pm 1$ & $61.2 \pm 1.6$ \\
\hline Liu et al., 2011 & $12 \mathrm{M}, 10 \mathrm{~F}$ & $23.9 \pm 0.4$ & $170 \pm 1$ & $61.2 \pm 1.6$ \\
\hline Yao et al., 2007 & $10 \mathrm{M}, 10 \mathrm{~F}$ & $25.3 \pm 3.0$ & $M: 172 \pm 4 / F: 161 \pm 5$ & $M: 63.6 \pm 6.2 / F: 52.6 \pm 5.6$ \\
\hline
\end{tabular}

\section{Experimental procedures}

The evaluation of the adopted experimental procedures is presented in Table 2. Climatic chambers were the most frequent experiment environment (Bogdan, 2011; Liu et al., 2015; Liu et al., 2011; Yao et al., 2007), and also a simulated aircraft cabin was considered (Fang et al., 2018). The acclimatisation of subjects in the local climatic conditions or previous to the experiments is referred to in two of the articles (Bogdan, 2011; Liu et al., 2015). Recommendations regarding behaviour before the experiments are presented in all articles, except for Bogdan (2011) and Fang et al. (2018). The review also assessed the experimental procedures adopted in the determination of the mean local skin temperature (Table 3). Skin temperatures were measured at a variety of measuring points over the reviewed articles. However, only in the work of Bogdan (2011), the skin temperature sensors were positioned in accordance with the ISO standard 9886:2004 (ISO, 2004). The calibration and level of precision of the test system are reported in most articles (Fang et al., 2018; Liu et al., 2015; Liu et al., 2011; Yao et al., 2007).

\section{Assessment of thermal comfort}

Table 4 assess the strategy adopted to assess thermal comfort through the skin temperature measurement in the reviewed articles. The thermal sensation seven-point scale, proposed by ASHRAE (2010) and harmonised in the ISO 7730:2005 (ISO, 2005) for the assessment of thermal sensation was applied in articles. All articles assessed local discomfort or thermal sensation (Yao 
et al., 2007; Bogdan, 2011; Liu et al., 2011; Liu et al., 2015; Fang et al., 2018). During experiments, it was also verified whether the subjects were sweating or shivering to verify if the thermoregulatory mechanisms had been activated in Bogdan (2011).

Table 2. Environmental conditions in the experiments

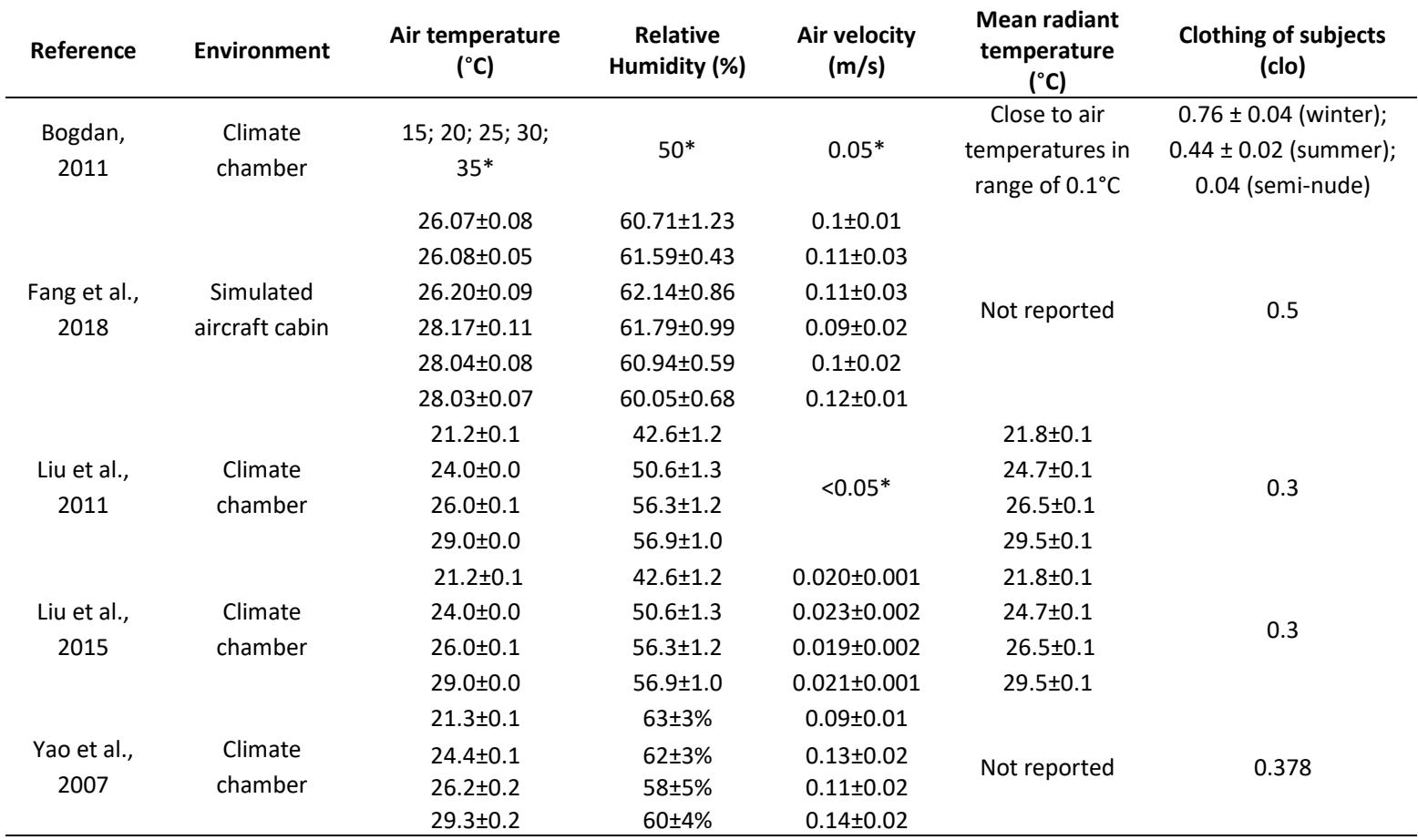

*Standard deviation not reported

Table 3. Experimental procedures for skin temperature measurement

\begin{tabular}{|c|c|c|c|c|c|}
\hline Reference & Position & Instrumentation & $\begin{array}{c}\text { Measuring } \\
\text { points }\end{array}$ & Location of sensors & $\begin{array}{c}\text { Skin temperature } \\
\text { parameter }\left({ }^{\circ} \mathrm{C}\right)\end{array}$ \\
\hline $\begin{array}{l}\text { Bogdan, } \\
2011\end{array}$ & Standing & Not specified & 14 & $\begin{array}{c}\text { Forehead, neck, right scapula, left } \\
\text { chest, right arm, left arm, left hand, } \\
\text { abdomen, paravertebral, right thigh, } \\
\text { left thigh, right shin, left calf, right } \\
\text { instep }\end{array}$ & $\begin{array}{l}\text { Mean local skin } \\
\text { temperature } \\
\text { values reported in } \\
\text { the graphics }\end{array}$ \\
\hline $\begin{array}{l}\text { Fang et al., } \\
2018\end{array}$ & Seating & $\begin{array}{l}\text { MP150 } 16 \text { channel } \\
\text { physiological signal } \\
\text { recording system } \\
\text { (BIOPAC) }\end{array}$ & 8 & $\begin{array}{c}\text { Forehead, chest; back, right upper } \\
\text { arm, right forearm, right hand, right } \\
\text { thigh, right calf }\end{array}$ & $\begin{array}{l}\text { Mean skin } \\
\text { temperature: } 33- \\
35\end{array}$ \\
\hline $\begin{array}{l}\text { Liu et al., } \\
2011\end{array}$ & Lying & $\begin{array}{l}\text { Copper-constantan } \\
\text { thermocouples } \\
\text { linked to a multi- } \\
\text { channel data } \\
\text { collector with } \\
\text { internal reference }\end{array}$ & 21 & $\begin{array}{c}\text { Forehead, left cheek, left neck, right } \\
\text { upper arm, left elbow, left forearm, } \\
\text { left palm, right hand, left hand, left } \\
\text { back, left chest, left lumbar, left } \\
\text { abdomen, left buttocks, anterior } \\
\text { thigh, posterior thigh, anterior calf, } \\
\text { posterior calf, left foot, right foot, } \\
\text { left sole }\end{array}$ & $\begin{array}{l}\text { Mean skin } \\
\text { temperature: } \\
\text { calculated }\end{array}$ \\
\hline $\begin{array}{l}\text { Liu et al., } \\
2015\end{array}$ & Lying & $\begin{array}{l}\text { junction (Keithley } \\
\text { Instruments) }\end{array}$ & 10 & $\begin{array}{l}\text { Forehead, chest, upper arm, back, } \\
\text { abdomen, elbow, hand, anterior } \\
\text { thigh, anterior calf, foot }\end{array}$ & $\begin{array}{l}\text { Mean skin } \\
\text { temperature: } \\
32.6-33.7\end{array}$ \\
\hline $\begin{array}{l}\text { Yao et al., } \\
2007\end{array}$ & Lying & $\begin{array}{l}\text { Copper-constantan } \\
\text { thermocouples }\end{array}$ & 16 & $\begin{array}{l}\text { Forehead, cheek, chest, upper arm, } \\
\text { abdomen, forearm, hand, anterior } \\
\text { thigh, anterior calf, foot, neck, } \\
\text { scapula, lumbar, posteromedial } \\
\text { thigh, posterior calf, anterior-medial } \\
\text { thigh }\end{array}$ & $\begin{array}{l}\text { Mean skin } \\
\text { temperature: } \\
\text { 32.7-33.5 }\end{array}$ \\
\hline
\end{tabular}


Table 4. Assessment of thermal comfort

\begin{tabular}{|c|c|c|c|}
\hline Reference & Thermal sensation & Type of assessment & Other assessment \\
\hline $\begin{array}{c}\text { Bogdan, } \\
2011\end{array}$ & $\begin{array}{l}\text { ASHRAE Seven-point thermal } \\
\text { sensation scale }\end{array}$ & $\begin{array}{l}\text { Scale applied to } 18 \\
\text { different body parts }\end{array}$ & $\begin{array}{l}\text { Included identification of shivering and skin } \\
\text { dampness }\end{array}$ \\
\hline $\begin{array}{l}\text { Fang et al., } \\
2018\end{array}$ & $\begin{array}{l}\text { ASHRAE Seven-point thermal } \\
\text { sensation scale }\end{array}$ & $\begin{array}{l}\text { Scale applied to } 3 \text { different } \\
\text { body parts }\end{array}$ & $\begin{array}{c}\text { Considered seven-point air movement } \\
\text { sensation scale: }-3 \text { (too still) to }(+3) \text { (too } \\
\text { windy) }\end{array}$ \\
\hline $\begin{array}{l}\text { Liu et al., } \\
2011\end{array}$ & $\begin{array}{l}\text { ASHRAE Seven-point thermal } \\
\text { sensation scale }\end{array}$ & $\begin{array}{c}\text { Not applied to a specific } \\
\text { body part }\end{array}$ & $\begin{array}{l}\text { Assessed thermal comfort in two levels: } \\
\text { comfortable or uncomfortable; } \\
\text { Included question about sweating }\end{array}$ \\
\hline $\begin{array}{l}\text { Liu et al., } \\
2015\end{array}$ & $\begin{array}{l}\text { ASHRAE Seven-point thermal } \\
\text { sensation scale }\end{array}$ & $\begin{array}{l}\text { Not applied to a specific } \\
\text { body part }\end{array}$ & $\begin{array}{c}\text { Assessed thermal comfort in three levels: } \\
\text { cool discomfort, comfort, and warm } \\
\text { discomfort }\end{array}$ \\
\hline $\begin{array}{l}\text { Yao et al., } \\
2007\end{array}$ & $\begin{array}{l}\text { ASHRAE Seven-point thermal } \\
\text { sensation scale }\end{array}$ & $\begin{array}{l}\text { Applied both to the overall } \\
\text { body and } 8 \text { body parts }\end{array}$ & $\begin{array}{l}\text { Considered five-point thermal comfort } \\
\text { scale: }+4 \text { (very comfortable) to }-4 \text { (very } \\
\text { uncomfortable) }\end{array}$ \\
\hline
\end{tabular}

Comparison of results

A comparison across the reviewed articles is difficult due to the variety of the adopted experimental conditions, particularly the environmental conditions and measurement points. Besides, the assessment of thermal comfort was not coincident over the articles, which makes it difficult to compare the results. However, all the reviewed articles stated that the thermal sensation or thermal comfort is closely related to the skin temperature of the body (Yao et al., 2007; Bogdan, 2011; Liu et al., 2011; Liu et al., 2015; Fang et al., 2018). Differences in mean skin temperature were found between males and females at the same thermal comfort level (Liu et al., 2015; Liu et al., 2011; Yao et al., 2007). The mean skin temperature of female subjects was smaller than the mean skin temperature of male subjects. However, at the level of warm discomfort, the mean skin temperature was almost the same for males and females (Liu et al., 2015; Liu et al., 2011; Yao et al., 2007). Regarding the environmental conditions, the environmental air temperature was considered the most important environmental factor affecting the human thermal comfort in Liu et al. (2011) and Liu et al. (2015). At an air temperature of $21^{\circ} \mathrm{C}$, most subjects felt uncomfortable with the sensation of cool or cold; at an air temperature of $29^{\circ} \mathrm{C}$, most subjects felt uncomfortably warm, with sweat at the hands, forehead, the chest and back. In the air temperatures of $24^{\circ} \mathrm{C}$ and $26^{\circ} \mathrm{C}$, all subjects felt thermal comfortable (Liu et al., 2011; Liu et al., 2015). The systematic review demonstrated that skin temperature is a good parameter to determine the thermal sensation vote and therefore, to assess thermal comfort in the whole body or specific parts of the body. From the articles it was possible to establish the connections: skin temperature and the thermal sensation (overall or local) regardless of being in the whole body or just specific regions, and the mean skin temperature with thermal sensation vote or thermal comfort level (Liu et al., 2011; Fang et al., 2018; Liu et al., 2015). To determine overall thermal comfort of the body, only the forehead, chest and abdomen appeared to be the best measuring points, with the highest correlation between thermal sensation and skin temperature (Bogdan 2011). This finding is in line with the ones reported by Fang et al. (2018) where the contribution of the upper body segments to the state of overall thermal comfort was more significant when compared to the lower body parts. The differentiation of comfort regarding skin temperature in different body segments was also observed in Yao et al. (2007).

\section{CONCLUSIONS}

This short systematic review sought to provide contributions to assess the linkage of thermal comfort and skin temperature in human subjects. This paper showed that skin temperature is a good indicator to determine the thermal sensation in specific parts of the body, being possible 
to establish a linear relationship between thermal sensation and skin temperature responses. A limitation of the findings of the selected articles is that all of them make use of a small population sample, which reflects into low statistical confidence of the obtained results. Also, the articles did not present the results for skin temperature at the time of thermal comfort (direct reporting). The reviewed articles have often considered different experimental procedures, which makes it challenging to conduct a fair comparison between the results. Future studies should be conducted considering more uniform procedures based on international standards, with the opportunity to expand the sampled population and conduct experiments considering different target groups, such as children or the elderly, to identify whether the prediction of the thermal comfort based on skin temperatures present the same trends when compared to the healthy adult population.

\section{References}

Allan, J. R. (1973). The Effects of Core Temperature Elevation and Thermal Sensation on Performance. Ergonomics, 16(2), 189-196. doi: 10.1080/00140137308924495

ASHRAE (American Society of Heating, Refrigerating and Air-Conditioning Engineers), 2010. ANSI/ASHRAE Standard 55-2010. Thermal Environmental Conditions for Human Occupancy. AHSRAE, USA.

Bogdan, A. (2011). Case Study Assessment of Local and General Thermal Comfort by Means of Local Skin Temperature. International Journal of Ventilation, 10(3), 291-300. doi: 10.1080/14733315.2011.11683956

Charkoudian, N. (2003). Skin Blood Flow in Adult Human Thermoregulation: How It Works, When It Does Not, and Why. Mayo Clinic Proceedings, 78(5), 603-612. doi: 10.4065/78.5.603

De Dear, R. J., Ring, J. W., \& Fanger, P. O. (1993). Thermal sensations resulting from sudden ambient temperature changes. Indoor air, 3(3), 181-192.

Fang, Z., Liu, H., Li, B., Cheng, Y. (2018). Thermal comfort and skin temperature responses to the supplied air from personal air nozzles in aircraft cabins. Indoor and Built Environment, 27(6), 831-845. doi: 10.1177/1420326X17692853

Grant, M. J., Booth, A. (2009). A typology of reviews: an analysis of 14 review types and associated methodologies. Health Information \& Libraries Journal, 26(2), 91-108. doi: 10.1111/j.1471-1842.2009.00848.x

ISO (International Organization for Standardization), 1998. ISO 7726:1998 - Ergonomics of the thermal environment -- Instruments for measuring physical quantities. International Organization for Standardization, Switzerland.

ISO, 2004. ISO 9886:2004 - Ergonomics - Evaluation of thermal strain by physiological measurements. International Organization for Standardization, Switzerland.

ISO, 2005. ISO 7730:2005 - Ergonomics of the thermal environment - Analytical determination and interpretation of thermal comfort using calculation of the PMV and PPD indices and local thermal comfort criteria. International Organization for Standardization, Switzerland.

Liu, W., Lian, Z., Deng, Q. (2015). Use of mean skin temperature in evaluation of individual thermal comfort for a person in a sleeping posture under steady thermal environment. Indoor and Built Environment, 24(4), 489-499. doi: $10.1177 / 1420326 \times 14527975$

Liu, W., Lian, Z., Deng, Q., Liu, Y. (2011). Evaluation of calculation methods of mean skin temperature for use in thermal comfort study. Building and Environment, 46(2), 478-488. doi: 10.1016/j.buildenv.2010.08.011

Moher, D., Liberati, A., Tetzlaff, J., Altman, D. G., and the, P. G. (2009a). Preferred Reporting Items for Systematic Reviews and Meta-Analyses: The PRISMA StatementThe PRISMA Statement. Annals of Internal Medicine, 151(4), 264269. doi: 10.7326/0003-4819-151-4-200908180-00135

Moher, D., Liberati, A., Tetzlaff, J., Altman, D. G., The, P. G. (2009b). Preferred Reporting Items for Systematic Reviews and Meta-Analyses: The PRISMA Statement. PLOS Medicine, 6(7), e1000097. doi: 10.1371/journal.pmed.1000097

Parsons, K., 2003. Human Thermal Environments, 2nd ed. Taylor \& Francis, United Kingdom.

Vasmatzidis, I. (2003). Effects of heat stress on cognitive performance: the current state of knowledge AU - Hancock, P. A. International Journal of Hyperthermia, 19(3), 355-372. doi: 10.1080/0265673021000054630

Yao, Y., Lian, Z., Liu, W., Shen, Q. (2007). Experimental Study on Skin Temperature and Thermal Comfort of the Human Body in a Recumbent Posture under Uniform Thermal Environments. Indoor and Built Environment, 16(6), 505-518. doi: $10.1177 / 1420326 \times 07084291$ 